Short communication

\title{
BIOAVAILABILITY OF BUTORPHANOL AFTER INTRANASAL ADMINISTRATION TO HORSES
}

\author{
V. FERREIRA, M. I. VELLOSO \& M. F. LANDONI \\ Cátedra de Farmacología, Facultad de Ciencias Veterinarias, Universidad \\ Nacional de La Plata, La Plata, Buenos Aires, Argentina
}

\begin{abstract}
Summary
Ferreira, V., M. I. Velloso \& M. F. Landoni, 2020. Bioavailability of butorphanol after intranasal administration to horses. Bulg. J. Vet. Med., 23, No 4, 443-447.

The aim of the present study was to describe butorphanol pharmacokinetics and bioavailability following intranasal administration to horses. Six adult horses received $0.05 \mathrm{mg} / \mathrm{kg}$ butorphanol, in a randomised crossover design, by either intravenous or intranasal route. Plasma concentrations of butorphanol were measured at predetermined time points using liquid chromatography/mass spectrometry assay. After intravenous injection, mean \pm SD butorphanol steady-state volume of distribution and clearance was $3.20 \pm 1.77 \mathrm{~L} / \mathrm{kg}$ and $3.18 \pm 1.47 \mathrm{~L} / \mathrm{kg} / \mathrm{h}$, respectively. Terminal half-lives for butorphanol after intravenous and intranasal administrations were $0.68 \pm 0.17 \mathrm{~h}$ and $1.79 \pm 1.43 \mathrm{~h}$. For intranasal administration, absorption half-life and peak plasma concentration were $0.43 \pm 0.33 \mathrm{~h}$ and $1.95 \pm 1.7 \mathrm{ng} / \mathrm{mL}$, respectively. Bioavailability was $54.45 \pm 20.09 \%$. Intranasal butorphanol administration in horses is practical, not stressful and well tolerated. Therefore, it might be a substitute to the intravenous route in adult horses.
\end{abstract}

Key words: bioavailability, butorphanol, horses, intranasal, pharmacokinetics

Butorphanol, a synthetic opioid agonistantagonist ( $\mu$-receptor antagonist and kreceptor agonist), is commonly used in equine medicine and is considered an efficacious and safe visceral analgesic in adult horses (Mama \& Hector, 2019). It causes minimal cardiovascular and respiratory effects and contributes to the management of balanced anaesthesia (McFadzean \& Love, 2018). Butorphanol in horses is commonly administrated by intravenous route.
The intranasal route of administration is not commonly used in horses. However, it is well tolerated (Ferreira et al., 2015) and has, in comparison with other administration routes, a number of advantages such as ease of administration and avoidance of first-pass metabolism.

The objective of the present study was to describe the pharmacokinetics and evaluate the bioavailability of butorphanol after intranasal administration to horses. 
Six healthy adult Standardbred horses, four castrated males and two females, were used for this study. Body weight ranged from 400 to $547 \mathrm{~kg}$ and age from 5 to 9 years. Horses were housed in box stalls and allowed free access to grass hay throughout treatment and observation periods. All experimental protocols were approved by the Institutional Animal Care and Use Committee, Faculty of Veterinary of the National University of La Plata. A two-way crossover trial was performed to determine the pharmacokinetics and bioavailability of intranasal (IN) butorphanol in horses. Horses were treated with intravenous (IV) $(n=3)$ or intranasal $(n=3)$ butorphanol at $0.05 \mathrm{mg} / \mathrm{kg}$. After a 2 week wash-out period treatments were reversed. Prior to administration, a $14 \mathrm{G}$ catheter was placed in the left jugular vein of each horse. A $14 \mathrm{G}$ catheter was also placed in the right jugular vein for drug administration in horses receiving intravenous butorphanol. The IV formulation used was a commercially available $1 \%$ aqueous solution (Butormin, Holliday-Scott, Argentina). The IN formulation, a $4.16 \%$ aqueous solution buffered to a $\mathrm{pH}$ value of 4.0 containing $0.33 \%$ sodium citrate, $0.64 \%$ sodium chloride and $0.64 \%$ citric acid, provided $8.3 \mathrm{mg}$ of butorphanol tartrate in a $0.2-\mathrm{mL}$ spray from a commercially available, single-dose metered sprayer (Coster Packaging, Argentina). For administration, the horses' heads were elevated for approximately $30 \mathrm{~s}$ during the administration and for approximately $30 \mathrm{~s}$ after the administration. No food or water was allowed until $4 \mathrm{~h}$ or $2 \mathrm{~h}$ after administration, respectively.

Blood samples were collected from the left jugular vein catheter prior to drug administration (time 0 ) and at 2.5, 5, 10, 15, 20, $30 \mathrm{~min}, 1,1.5,2,3,4,6,8,10$ and $12 \mathrm{~h}$ after IV or IN administration. Blood samples were immediately injected into a heparinised glass tube and stored on ice until centrifuged for collection of plasma. Plasma was stored at $-80{ }^{\circ} \mathrm{C}$ until butorphanol concentrations were measured.

Plasma butorphanol concentrations were determined by LC-MS as described elsewhere (Knych et al., 2013). The method was linear between 0.05 and 50 $\mathrm{ng} / \mathrm{mL}$, intraday and interday variation was less than $15 \%$ and LOQ was 0.1 $\mathrm{ng} / \mathrm{mL}$.

Nonlinear least square regression analysis was performed on plasma butorphanol concentration vs. time data from both treated groups, using commercially available software (WinNonlin Version 5.0, Pharsight, Cary, NC, USA). Only data points (plasma concentrations) equal to or above the LOQ were included in the analysis.

Pharmacokinetic parameters are reported as mean $\pm \mathrm{SD}$ (Table 1). Main pharmacokinetic parameters were statistically compared for the two administration routes, applying Wilcoxon test. Differences were considered statistically significant when $\mathrm{P} \leq 0.05$.

No adverse effects were observed in any of the experimental animals. Butorfanol plasma concentration vs. time curves after IV and IN administration were best described by an open monoexponential model in all the horses (Fig. 1).

After IV and IN administration, plasma concentrations were maintained above the limit of quantification $(0.1 \mathrm{ng} / \mathrm{mL})$ until the $4^{\text {th }}$ post-administration hour in all the experimental animals. In 5 animals concentrations were above LOQ until the $8^{\text {th }}$ post-administration hour. After intranasal administration, concentrations were lower than those observed after intravenous administration. The average peak concentration was $1.95 \pm 1.75 \mathrm{ng} / \mathrm{mL}$ and 
Table 1. Mean pharmacokinetic parameters of butorphanol after IV and IN administration to horses at a dose rate of $0.05 \mathrm{mg} / \mathrm{kg}(\mathrm{n}=6)$

\begin{tabular}{|c|c|c|c|c|}
\hline & \multicolumn{2}{|c|}{ Intravenous } & \multicolumn{2}{|c|}{ Intranasal } \\
\hline & Mean & SD & Mean & SD \\
\hline Actual dose (mg/kg) & 0.050 & 0.000 & 0.047 & 0.001 \\
\hline $\operatorname{Kel}(\mathrm{L} / \mathrm{h})$ & 1.070 & 0.260 & 0.514 & 0.273 \\
\hline $\mathrm{T}^{1} / 2$ el $(\mathrm{h})$ & 0.681 & 0.169 & 1.794 & 1.429 \\
\hline $\operatorname{Kabs}(\mathrm{L} / \mathrm{h})$ & - & - & 3.494 & 3.788 \\
\hline $\mathrm{T}^{1 / 2}$ abs (h) & - & - & 0.426 & 0.320 \\
\hline $\operatorname{Tmax}(\mathrm{h})$ & - & - & 1.487 & 0.765 \\
\hline $\mathrm{C} 0 / \mathrm{Cmax}(\mathrm{ng} / \mathrm{mL})$ & 28.883 & 35.818 & 2.490 & 1.778 \\
\hline $\operatorname{AUC}_{0-\infty}(\mathrm{ng} \cdot \mathrm{h} / \mathrm{mL})$ & 25.220 & 27.395 & 14.437 & 17.055 \\
\hline $\mathrm{Vd}(\mathrm{L} / \mathrm{kg})$ & 3.204 & 1.772 & 5.367 & 4.980 \\
\hline $\mathrm{ClB}(\mathrm{L} / \mathrm{h} / \mathrm{kg})$ & 3.188 & 1.477 & 2.998 & 1.378 \\
\hline F (\%) & - & - & 54.454 & 20.091 \\
\hline
\end{tabular}

Kel, elimination rate constant; $\mathrm{T}^{1} \frac{1}{2} \mathrm{el}$, elimination half-life; Kabs, absorption rate constant; $\mathrm{T}^{1} 1 / 2$ abs, absorption half life; Tmax, time of peak concentration; $\mathrm{C} 0$, concentration at zero time; Cmax, peak concentration; $\mathrm{AUC}_{0-\infty}$, area under the plasma concentration vs. time curve from 0 to $\infty ; \mathrm{Vd}$, volume of distribution (corrected by F); ClB, body clearance (corrected by F) ; F, bioavailability.

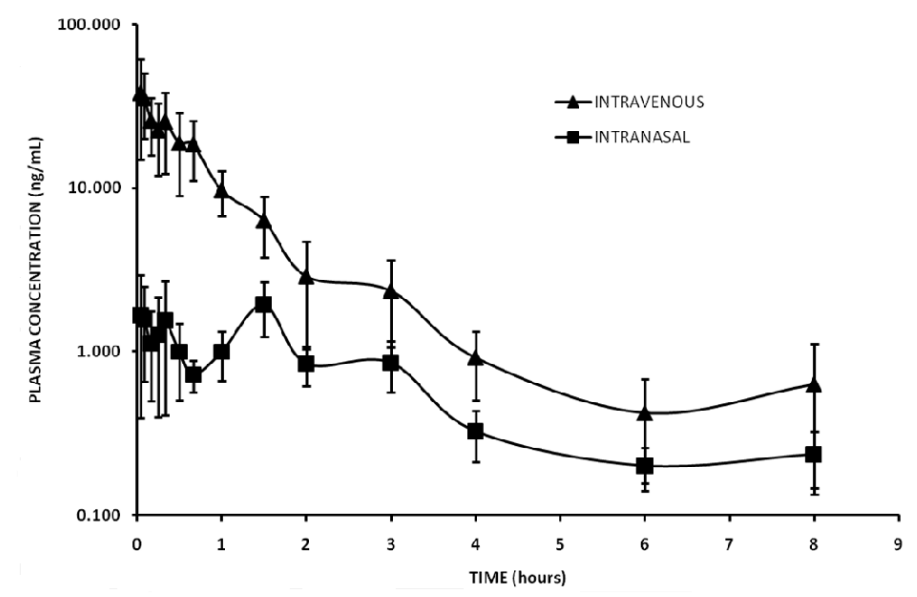

Fig. 1. Plasma concentration of butorphanol (mean $\pm S D ; n=6)$ vs. time after intravenous and intranasal administration at a dose rate of $0.05 \mathrm{mg} / \mathrm{kg}$ to horses.

was presented at 2 hours post-administration. Inter-subject variability, especially in early sample times, was important.

After intravenous administration, butorphanol was widely distributed, with a volume of distribution of $3.20 \pm 1.77 \mathrm{~L} / \mathrm{kg}$. A single experimental animal showed outlier type distribution volume. The values calculated in the rest of horses $(2.06 \pm 1.2$ $\mathrm{L} / \mathrm{kg}$ ) were slightly higher than those re- 
ported by other authors (Sellon et al., 2009; Knych et al., 2013; Chiavaccini et al., 2015). Elimination was rapid, with a body clearance of $3.19 \pm 1.48 \mathrm{~L} / \mathrm{h} / \mathrm{kg}$. The rapid elimination was also reflected by the short half-life $(0.681 \pm 0.169 \mathrm{~h})$. The estimated clearance was higher than those reported for other authors (Sellon et al., 2009; Chiavaccini et al., 2015). It is difficult to explain the differences observed between previous studies and the present study. One explanation is related to the polymorphism in CYP2D50 (Corado et $a l ., 2016)$, the cytochrome involved in the metabolism of most opioids; in humans the high polymorphism of CYP2D6, the orthologue to equine CYP2D50, leads to ultrarapid metabolisers (St Sauver et al., 2017), as in this study. Unfortunately, there are no comprehensive data on butorphanol metabolism in horses.

Absorption after IN administration, was relatively rapid ( $\mathrm{T}^{1} \frac{2}{2}$ abs: $0.426 \pm$ $0.320 \mathrm{~h}$ ) with a bioavailability of $54.45 \pm$ $20.09 \%$. This is lower than the value reported after SC (87\%) (Chiavaccini et al., 2015), but higher than after IM administration (37.3 $\pm 6.1 \%)$ (Sellon et al., 2009). It is important to highlight that in the present study blood was sampled in the external jugular vein and blood perfusing the nasal cavity drains in that same vein. It is therefore likely that the samples were not adequately mixed and bioavailability may be an overestimation of the actual systemic availability (Hedges et al., 2013). Maximum observed concentration (Cmax) was $2.49 \pm 1.78 \mathrm{ng} / \mathrm{mL}$ with a Tmax of $1.48 \pm 0.76 \mathrm{~h}$. The $\mathrm{Vd}$, corrected for bioavailability, was $5.36 \pm 4.98 \mathrm{~L} / \mathrm{kg}$, the important intersubject variability reflects the high value observed in two equines. The $\mathrm{ClB}$, corrected for bioavailability, was very similar to that estimated after intravenous administration $(2.99 \pm 1.37 \mathrm{~L} / \mathrm{h} / \mathrm{kg})$, reflecting the rapid elimination of the molecule. Elimination half-life was $1.79 \pm 1.42 \mathrm{~h}$. None of the estimated pharmacokinetic parameters was statistically different from the IV route.

The intranasal administration in horses is practical, not stressful and well tolerated (Ferreira et al., 2015) besides allows bypassing the blood-brain barrier (Dhuria et al., 2010) by different pathways (Djupesland et al., 2014), all of them related to the olfactory function. Considering that horses communicate through odours, it is expected that CNS-acting drugs suffer important transport from the nose to the CNS, transforming the IN route in a valuable therapeutic alternative.

\section{ACKNOWLEDGEMENTS}

This work was supported by the National Agency of Science and Technology, Argentina (PICT 2015-0926)

\section{REFERENCES}

Chiavaccini, L., A. K. Claude, J. H. Lee, M. K. Ross, R. E. Meyer \& V. C. Langston, 2015. Pharmacokinetics and pharmacodynamics comparison between subcutaneous and intravenous butorphanol administration in horses. Journal of Veterinary Pharmacology and Therapeutics, 38, 365374.

Corado, C. R., D. S. McKemie, A. Young \& H. K. Knych, 2016. Evidence for polymorphism in the cytochrome P450 2D50 gene in horses. Journal of Veterinary Pharmacology and Therapeutics, 39, 245254.

Dhuria, S.V., L. R. Hanson \& W. H. Frey, 2010. Intranasal delivery to the central nervous system: Mechanisms and experimental considerations. Journal of Pharmaceutical Science, 99, 1654-1673. 
Djupesland, P.G., J. C. Messina \& R. A. Mahmoud, 2014. The nasal approach to delivering treatment for brain diseases: An anatomic, physiologic, and delivery technology overview. Therapeutic Delivery, 5, 709-733.

Ferreira, V., O.Teme Centurion \& M. F. Landoni, 2015. Evaluación de la vía intranasal para la administración de opioides en equinos. Invet, 17, 63-64.

Hedges, A.R. B. H. Pypendop, Y. Shilo, S. D. Stanley \& J. E. Ilkiw. 2014. Impact of the blood sampling site on time-concentration drug profiles following intravenous or buccal drug administration. Journal of Veterinary Pharmacology and Therapeutics, 37, 145-150.

Knych, H. K., H. C. Casbeer, D. S. McKemie \& R. M. Arthur, 2013. Pharmacokinetics and pharmacodynamics of butorphanol following intravenous administration to the horse. Journal of Veterinary Pharmacology and Therapeutics, 36, 21-30.

Mama, K. R. \& R. C. Hector, 2019. Therapeutic developments in equine pain management. The Veterinary Journal, 247, 50-56.
McFadzean, W. J. M. \& E. J. Love, 2018. Perioperative pain management in horses. Equine Veterinary Education. https:// doi.org/10.1111/eve.12880.

Sellon, D. C., M. G. Papich, L.Palmer \& B. Remund, 2009. Pharmacokinetics of butorphanol in horses after intramuscular injection. Journal of Veterinary Pharmacology and Therapeutics, 32, 62-65.

St Sauver, J. L., J. E. Olson \& V. L. Roger, 2017. CYP2D6 phenotypes are associated with adverse outcomes related to opioid medications. Pharmagenomics and Personalized Medicine, 10, 217-227.

Paper received 02.03.2019; accepted for publication 26.05.2019

\section{Correspondence:}

Maria Fabiana Landoni

Calle 60 y 118, (1900),

La Plata, Buenos Aires, Argentina

e-mail: landoni@fcv.unlp.edu.ar 